\title{
Designing Undergraduate Degree Programmes
}

1 Introduction

1.1 Definitions and coverage

1.2 Key considerations in the preparatory stages of course design

1.3 Centralisation of the course design process

2 Undergraduate degree programmes

2.1 The programme structure

2.2 Course design

2.3 Unit/module provision and progression

2.4 Making programmes more inclusive

Appendix BA Economics: an example of a programme specification 


\section{Introduction}

\subsection{Definitions and coverage}

This chapter is intended as an aid for anyone who is undertaking the task of designing an undergraduate degree programme. Course design has become increasingly complex with the decision by universities to incorporate more subject-specific degrees into their undergraduate profiles in an attempt to attract larger numbers of students each year. This move has increased the provision of undergraduate programmes principally through more extensive intra- and cross-faculty collaboration. In addition, the changes have put added pressure on timetabling systems and have meant that institutions have had to become more aware of the issue of key skills, options and programme learning outcomes, particularly in cases where units/modules and courses are shared with other faculties/schools.

Structures and procedures differ from institution to institution. This chapter uses particular terms, such as units, modules, Boards of Studies, faculties and so on, which may not correspond exactly with titles or arrangements at different universities. However, the expectation is that each term will find an approximate translation to the circumstances of each institution.

There are numerous issues that need consideration in the development of a successful undergraduate programme and the following guide seeks to provide detailed information about this process. Sections 1.2 and 1.3 introduce the main areas for consideration, while section 2 provides detailed information about the process of course design and the issues that play a crucial role in the development of undergraduate programmes.

\subsection{Key considerations in the preparatory stages of course design}

\section{QAA issues and benchmarking statements}

The Quality Assessment Agency benchmarking statements are probably the best place to begin when planning a new undergraduate programme. These statements are clear indicators of the requirements of any course in economics and, although fairly open ended, they can act as a valuable guide when formulating the structure and content of a new undergraduate degree programme. As stated in the QAA documentation:

Subject benchmark statements set out expectations about standards of honours degrees in broad subject areas. They are about the conceptual framework that gives a discipline its coherence and identity, and they define what can be expected of a graduate in terms of the techniques and skills needed to develop understanding in the subject. They are benchmarks of the level of intellectual demand and challenge represented by an honours degree in the subject area concerned.

Benchmark statements help higher education institutions when they design and approve programmes. The statements help external examiners and academic reviewers to verify and compare standards. They also provide information for students and employers.

QAA benchmark statements for economics dictate that university undergraduate degree programmes in economics and economic subject-related disciplines should: 
- provide an in-depth knowledge of economics and enable students to apply the knowledge and understanding gained in this subject area;

- enable students to study and apply the principles of economics to different types of practical situation that will be useful for future employment;

- encourage ongoing critical, evaluative and strategic ways of thinking in all areas;

- recognise the importance of the industry-education relationship and offer opportunities for learning in other environments;

- enable students to undertake relevant postgraduate study;

- provide successful graduates of the programme with an educational and training profile that will equip them for employment in a range of sectors.

As summarised by Livingstone and Matthews (2000): 'The intention is that these subject-based benchmarks should provide explicit standards against which all degree courses in the country can be judged. More specifically the benchmark should provide an indication of the capabilities that we should expect of graduates of a particular subject, regardless of the institution of graduation.'

\section{Programme specification}

According to the QAA documentation:

Programme specifications are standard sets of information that each institution provides about its programmes. Each specification clarifies what knowledge, understanding, skills and other attributes a student will have developed on successfully completing a specific programme. It also provides details of teaching and learning methods, assessment, and subsequent career opportunities, and sets out how the programme relates to the qualifications framework.

This information allows prospective students to make comparisons and informed choices about the programmes they wish to study and provides useful guidance for recruiters of graduates.

Thus programme specifications draw all of the relevant information about the course together and present it clearly for the purposes of validation and student reference. The content of a programme specification normally includes:

- educational aims of the programme;

- learning outcomes of the programme;

- programme structure;

- support for student learning;

- admissions requirements;

- evaluation, quality assurance and maintenance of standards;

- regulation of assessment;

- indicators of quality and standards;

- references;

- mapping of:

- key skills

- curriculum skills

- assessment. 


\section{Transferable skills}

Transferable skills, or key skills, are now an essential feature in the course design process. In many cases the impetus for the introduction of key skills into undergraduate degree programmes has come from graduates and employers who have commented that students graduating with UK degrees often have good subject knowledge but are weak on key skills.

Employability is a key feature of any new undergraduate programme design process. The 'SkillsPlus' project, a joint venture by Lancaster, Manchester Metropolitan, Liverpool John Moores and Manchester universities, has been developed to identify ways of designing undergraduate programmes in order to enhance student employability and may prove to be a useful reference tool when considering how best to incorporate key skills into a specific programme.

In fact, key skills are already an implicit feature of most undergraduate degree programmes in economics, although until recently we have not been required to make the process of key skill acquisition explicit in the documentation of each available programme. As a result, we have been teaching and assessing key skills for several years, but without the documented mapping of these skills, our knowledge of the achievement by students in the area of key skill acquisition has always been somewhat patchy.

It is now a requirement of course design that we identify the key skills that a student will learn throughout a given programme and provide details about where and how these skills will be learned. Thus the programme specification needs to identify where each skill is being taught and what assessment is being used to document student achievement in this area. By tracking the process of key skill teaching throughout the programme, we are then able to ensure that no skill is overlooked through the process of option selection and we are able to assure prospective employers that specific targets and achievements have been met. This can be achieved through careful programme design and incorporating a key skills mapping exercise into the programme specification, which will enable you to identify clearly where students will attain and be evaluated in each skill. This in turn will enable you to ensure that at the curriculum/syllabus design stage you are building on what has gone before, thereby laying the foundations for units/modules that you might wish to incorporate into the later stages of the course.

Greater emphasis on lifelong learning, widening participation and other government initiatives has meant that the process of course delivery in higher education has had to change to meet the needs of this wider group of prospective students. While this guide is not intended to debate the value of the contribution of key skills to the undergraduate degree programme, it is worth noting that the incorporation of key skills and the recording of skill acquisition in programme specifications and programme learning outcomes serves to clarify the objectives of a course to a potential student.

The Higher Education Funding Council for England (HEFCE) has often commented that despite claims that different subject areas are making efforts to develop transferable skills in order to enhance the employability of their students, few examples have surfaced in quality audits related to consultations with employers about the structure and content of the undergraduate programme curriculum.

In response, many economics departments in the UK have introduced stronger links with employers both through the addition of an optional placement year and through Employer Advisory Committees. This has enabled departments to discuss first hand the types of skills, knowledge and qualities that

\begin{tabular}{|l|}
\hline \multicolumn{1}{|c|}{ TOP } \\
\hline Reference to information \\
from the South East Education \\
Development Agency (SEEDA) \\
about key skill development \\
and the link between course \\
design and employability can \\
be useful when considering \\
how units/modules link \\
together within a specific \\
programme.
\end{tabular}
employers most value. Such information has then been incorporated into new and existing undergraduate degree programmes in an attempt to make them more attractive to prospective students. This has largely been a valuable exercise. In many cases the discussions have led to additional skills-based exercises in units/modules throughout the undergraduate programme and has made employers more aware of the skills that students acquire during their 
undergraduate studies. In the increasingly competitive environment of higher education, students want concrete information about their employment prospects prior to joining a programme at any given institution. Thus visible links with employers, the acknowledgement that an undergraduate programme has incorporated skills specifically required by employers, and the ability to show strong graduate employment statistics are now essential features of the success of any undergraduate programme.

\subsection{Centralisation of the course design process}

Centralisation of the course design process often helps in the coherence of the final programme structure. In the case of single honours degrees, having one person or a small team of people within a department who consider the syllabus, map course-unit or course-module links, identify learning outcomes, etc. ensures consistency both within the degree structure and across existing degrees. In the case of joint honours degrees, the centralisation process becomes even more important.

In addition to the issues related to single honours degree programmes, joint degrees, whether intra-faculty or cross-faculty, come with additional pitfalls. Learning outcomes for both subject areas need to be clearly defined and properly linked so that the marketing aspects of the course are convincing. Greater attention needs to be paid to the mapping of curriculum and key skills to ensure that there is balance between the two subject areas. Also, assessment patterns often emerge within a single department that complement the programme in which the units/modules naturally sit. Thus, over time, the assessment patterns for units/modules taught in the economics department have been amended to provide students with a balance of assessment that works well within the constraints of the academic year. Combining units/modules from an economics degree with those from another faculty or department that has its own successful assessment pattern may, initially, provide students with an unbalanced schedule of assessment in their programme. Thus the teaching of key skills, the assessment patterns and the balance of units/modules offered at each stage of the programme need to be carefully considered by those who can oversee the whole process to ensure consistency and balance.

In the case of joint degrees it is also necessary to consider the issue of course management. While one department will own and administer the degree, the input from the other department

TOP
TIPS

Greater commitment by staff and more effective course management may be achieved by linking the programme to processes employed by each department for the monitoring of standards and quality. Thus including these programmes in both Boards of Studies will encourage all staff to identify and engage with the programme. is essential for the smooth running of the programme and to ensure that students on the joint degree feel properly informed and managed. All too often the management of a joint programme is not clearly defined and students on the course lack the sense of belonging and support that is provided to single honours degree students. This problem can persist from the initial induction phase through to the provision of information, timetable arrangements where travel is required between two or more sites, and the degree of interest that students sense from the staff who are participating in, but not administering, the degree course. Where the degree is a collaborative effort between departments there may be less enthusiasm by staff to engage in the student learning experience outside of the lecture theatre or seminar sessions.

To escape this pitfall it is important that, when the degree is introduced, the course administrator has a liaison person from the joint department involved who can participate in student support, contribute to the induction programme, advise students on academic issues and be consulted for further information about programme issues where necessary. This sounds logical, but it is worth noting that it is often difficult to sustain interest and support from a department participating in a joint degree if it is not immediately responsible for the administration of that course. Ensuring that someone is assigned to this task and takes ownership at an early stage in the course design process is essential for successful course management. 


\section{Undergraduate degree programmes}

\subsection{The programme structure}

Undergraduate courses can take a variety of forms that can make the process of designing a new degree less prescriptive than it used to be. Universities are becoming increasingly committed to the development of joint honours programmes in response to employer and student demands. As these joint degrees have become more popular, so further institutions have looked at the opportunity of introducing such courses in order to compete effectively with other institutions. It is anticipated that within eight years, 10-20 per cent of full-time undergraduate students will be enrolled on joint honours programmes. Such programmes may be either within the same faculty/school or across different schools, and may involve many different subject areas. When designing a joint degree, consideration needs to be given to study skills, career units/modules, research methods, fieldwork and/or placements so as not to disadvantage the student in either of the joint areas studied.

Single honours degrees are easier to construct, in terms of both collecting suitable units/modules together and introducing new units/modules to fill necessary gaps in the curriculum. These fit neatly into a previously designed structure of syllabus flow, key skill and curriculum skill development, research agendas and assessment patterns. The task becomes more complicated when embarking on the design process for an intra-faculty/school programme or a crossfaculty/school programme where no formal structure exists that can be referred to for the purposes of learning outcomes, the flow of skills and the fair distribution of assessment throughout the programme. More difficult still is designing those programmes that also fall outside of the conventional 3-4-year undergraduate programme - for example, courses that offer direct entry to a given level or those courses that have a mid-year start.

\subsection{Course design}

It is best to consider first the overall picture of course design and then to pull ideas together in the form of a programme specification. The cross-referencing and justification that occurs in the production of a programme specification can ensure that all necessary links are made between key skills, curriculum skills, benchmark statements, student achievement and unit/module delivery.

Essentially the curriculum is an interaction between aims and objectives, methods of assessment, teaching methods and content. With respect to the teaching methods to be incorporated into the programme, it is worth noting that the way in which students are taught affects the student experience. Choice, and varying teaching methods and assessment, may even be of greater significance to what students learn than the content that is being taught.

An example of a programme specification is included as an appendix to this chapter. Those areas of the programme specification that relate specifically to course design are discussed in greater depth below. The content and structure of the programme specification as a vehicle for successful programme design is best illustrated through Figure 1. 


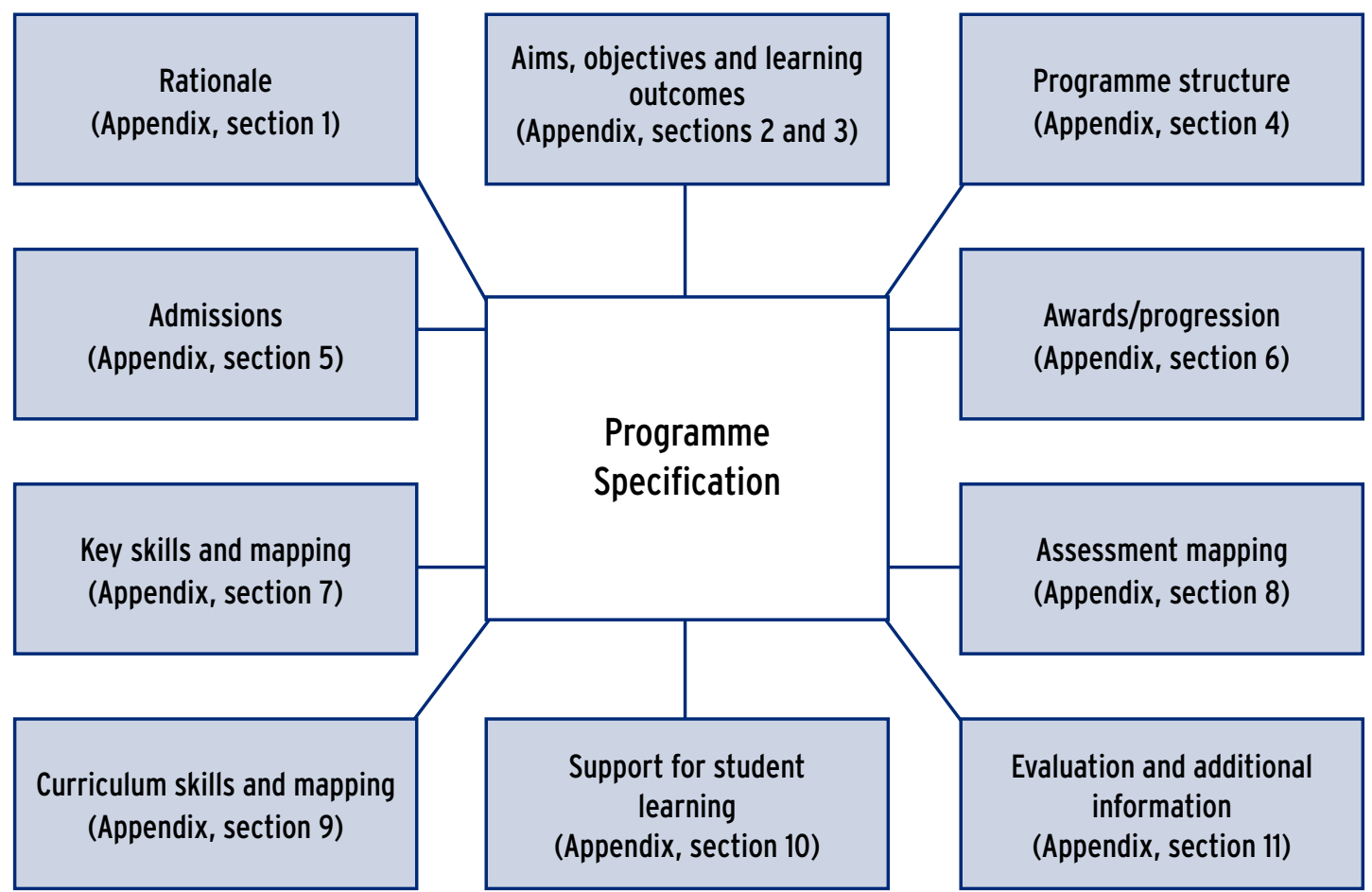

Figure 1 Content and structure of the programme specification

\section{Initial course proposal}

To begin the process of course design, you should ask yourself the following questions:

- Why is this course being taught?

- What new levels of knowledge, understanding and skills will the students achieve during the course?

- What knowledge, understanding and skills are required prior to students joining the course?

- What forms of teaching, learning and assessment will help students to gain the knowledge, understanding and skills to complete the course successfully?

- What can be offered to enrich and add value to the overall student learning experience with the resources available?

- What teaching resources are available and how can they best be used?

TOP

TIPS

Considering the above questions throughout the process of course design will help you to ensure that you remain focused on the purpose of the new degree course. The answers to these questions will also be useful in the production of marketing materials.
- What undergraduate course structure would best suit the course outcomes? What units/modules will be most appropriate, what order should they be taught in, and what type of option/elective system will students be offered?

- What assessment patterns and monitoring processes will be used to track student and course progress?

Bear in mind that you want to create a course that encourages students to think like economists and to engage enthusiastically in the material learned. Thus unit/module structure, the ordering of units/modules, the variety of assessment, options and electives, and additional course features (field trips, work experience, exchange programmes) are all essential factors in designing a course that will be attractive to students. 


\section{Rationale}

To ensure that the programme that you are introducing makes strategic sense for the department and the university as a whole, you should consider a number of key points. First, you need to identify the intention behind the development of the course proposal - is it addressing a gap in the market, is there evidence of student or employer demand, etc? - and consider how the new programme will fit into the strategic plans of the university and the faculty. Secondly, you need to consider the market for such a course and whether there will be sufficient demand. In addition, you need to identify what differentiates your course from those offered elsewhere. Finally, it is worth considering the possible impact of this course on other courses offered by the institution. For instance, if you are developing a course in economics and mathematics, you need to consider the likelihood that this will take numbers away from the single honours degrees in these subject areas.

Useful marketing data that can help you to determine student demand is available from the UCAS website (http://www.ucas.ac.uk). This can provide you with information about the demand for single and joint honours courses

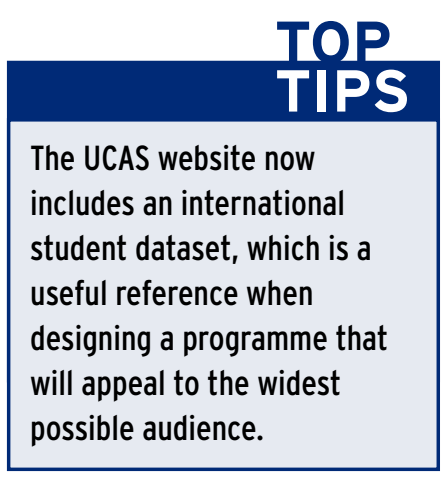
in different subject areas, your competitors (those institutions that your students also applied to) and the courses that students applied for at other institutions. This is particularly useful when considering the types of course that are offered by your competitors and the programmes that are being chosen by prospective students, as it can help you to decide which programmes might recruit well at your institution.

\section{Aims, objectives and learning outcomes}

Considering the aims and objectives of the new course is an important first step in curriculum design. Aims are general statements that relate to the overall orientation of a course, while objectives are more detailed statements about what a student should actually be able to do if they successfully complete the course.

Aims, objectives and learning outcomes of the course should really incorporate the principal benchmarking statements for any of the subject areas participating in the degree programme. Thus single honours degree programmes should cover all the benchmarking statements in the programme learning outcomes, while a joint degree would have learning outcomes that were a combination of the benchmarking statements from the two subject areas. Outcomes of the course may also be drawn from the undergraduate curriculum framework, the institution's policy on key skills, scholarship and research expertise of academic members of staff, and the National Qualifications Framework.

Expectations of student achievement are generally presented in the form of learning outcomes. Programme learning outcomes include the curriculum skills (knowledge and understanding, cognitive skills and practical skills) that students are expected to acquire during the programme of study. Teaching, learning and assessment patterns are then linked to the programme learning outcomes in order to identify whether the objectives of the course are being met. An example of the link between programme learning outcomes and teaching, learning and assessment strategies is presented in the appendix, section 3.

\section{Bottom-up, top-down and middle-out approaches}

There are a number of ways in which to approach undergraduate course design. The bottom-up approach involves all the relevant units being selected and then linked together in order to create a complete undergraduate course. 
Alternatively, a top-down approach can be used which involves developing a more global picture of the undergraduate programme - the purpose, the topics that need to be incorporated into the curriculum, etc. - and then selecting those units that fulfil the overall course framework. Some argue that this approach gives the final programme structure greater integrity and a better balance of units/modules across the curriculum because units/modules have been chosen to achieve a specific goal, a factor that is missing in the bottom-up approach. Thus the course design team would decide on a logical progression of content and skills, a specific level of specialisation as the students move from one level to the next, varied assessment methods, the opportunity for students to participate in an exchange, work placement or field trip, etc. They would also consider the type of option/elective system that will be offered to students on the degree (restricted/unrestricted options, restricted/unrestricted electives) and the specific model to be used for the undergraduate programme. Units/modules would then be selected to meet the aims of the programme.

The middle-out approach is considered by some to be the best combination of the previous two approaches to course design. This involves the course design team bouncing between the strategic issues of course design (the aims of the course, the balance of teaching, learning and assessment methods, continued development of key skills throughout the programme, etc.), and the specific unit/modules that they want to incorporate into the new programme. The combination of these two layers can ensure that the course design process benefits from attention at both the strategic and the unit/module level, which should help to deliver a more balanced and innovative programme.

There is no right or wrong approach to take. It is just important that those involved in the course design process are aware of the different routes available in order to decide what would best suit the process in their institution. Ultimately you want to use this information to ensure that the programme that you design has purpose, justification, logical flow and a specific set of outcomes. Also you want to create a programme that offers students a solid foundation in economics and enables them to develop their interests further through a selection of subjectspecific options. Tackling these issues at the initial stages of programme design helps to ensure that the final product will be of a high quality.

\section{Consistency/balance}

All programmes should have constructive alignment. Programmes should seek to engage students in a variety of learning activities that produce compatibility between curriculum, teaching methods and assessment procedures. Essentially the final curriculum is an interaction between aims and objectives, methods of assessment, teaching methods and content. With respect to the teaching methods to be incorporated into the programme, it is worth noting that the way in which students are taught dramatically affects the student experience. Choice, and the use of different teaching methods, may even be more significant to what students learn than the content that is being taught. In addition, changing any one element of teaching or assessment will affect the balance of the overall learning experience, and changes in assessment will certainly change the way in which students view material and learn.

Balance in a programme is achieved, in part, through the provision of a variety of learning and assessment modes. A programme that incorporates problem-based learning, research skills, presentations, computer-based learning, etc. enables students to gain both a thorough understanding of economics and a proficiency in transferable skills that will make them more employable. Thus programmes that focus on both of these elements will ultimately lead to courses that are more attractive to prospective students.

It is also worth considering the extent to which you want to encourage the development of personal interest in the course design process. Some lecturers like to incorporate their research 
interests into their teaching and assessment, which can increase staff motivation for teaching and can, through the depth of the lecturer's research experience, make a unit/module more interesting for students. Be aware, though, that the curriculum is likely to become unbalanced if a very high proportion of the undergraduate curriculum is informed by specific staff research interests. It is essential that the curriculum also focus on wider issues such as key skills development, the application of relevant materials, varied assessment patterns that will sustain student interest, etc. Thus incorporating research into teaching can be valuable for students as long as it is balanced with other key learning activities.

\section{Assessment}

When designing an undergraduate degree programme it is useful to consider what skills we would like our students to know, and be able to achieve, by the time they complete the degree course. By deciding what you would like the students to achieve, you can then build a balanced selection of assessment methods into the programme and map the specific skills that will be demonstrated in each unit/module.

Firstly, you should consider the learning objectives and the expected outcomes of the units/modules that students will take during their programme. You then need to consider how these outcomes will be assessed and whether the assessment patterns in the different units/modules are suitable and balanced. For example, at level 1 you might require students to participate in group assignments or presentations in order to demonstrate the ability to work effectively as part of a team. At level 2 you might add to these skills by requiring students to combine their team and presentational skills with the ability to think critically and identify strengths and/or weaknesses in a given argument. At level 3 you might then encourage students to expand these skills by providing them with the opportunity to participate in peer assessment and to demonstrate an ability to apply previous knowledge to the development of ideas and theories. This might also include the requirement that students use original ideas to explain and present previously learned theories in a variety of economic contexts.

The assessment techniques used at each stage need to reflect the learning outcomes for the programme. Thus you need to ensure that the programme offers a wide variety of assessment patterns to enable students properly to demonstrate a wide range of taught skills. For instance, if a programme has a learning outcome that requires students to communicate effectively orally, then it would perhaps be useful to have some assessment practices at each level that incorporate both individual and group presentations. Alternatively, if a programme requires students to create links between different subject areas, then it would be useful to incorporate some essay-based assessment or assignments that require students to draw on skills learned in different subject areas.

Overall it is essential to incorporate a wide variety of different assessment patterns into each programme so that at each level the students are given the opportunity to develop, exploit and recognise their strengths. The

Using the course design phase
of a new programme to
encourage the incorporation
of a wider range of
assessment modes can
encourage staff to strengthen
the delivery and provision of
established units/modules on
other programmes.
It is useful to create an
assessment map to clarify the
types of assessment method
that will be used across the
programme. This will help you
to ensure that the
assessment pattern is
balanced at each level of the
degree course.
combination of presentations, problem-based assessment, essays, computer-based assessment, teamwork, driving tests, quizzes, etc. enables students to demonstrate to future employers that they have a proven ability in a wide range of areas while also giving the students the opportunity to excel in certain areas, which can contribute to continued student motivation and enthusiasm. 


\section{Curriculum skills}

Curriculum skills relate to the knowledge and understanding, cognitive skills and practical skills that you require a student to achieve if they follow the degree programme. For a single honours economics degree, this might include the following skills.

1. Knowledge and understanding of:

- fundamentals/principles of economics;

- the basic tools of economic analysis;

- economic theory and practice;

- quantitative methods and computing techniques relevant to the study of economics;

- the use of data, both quantitative and qualitative, relevant to the study of economics;

- the relevance of economics to the study of society;

- the application of specialist knowledge.

2. Cognitive skills

- Identify, define and explore economic issues.

- Identify tacit assumptions and limitations of data and information.

- Analyse and evaluate evidence.

- Expound findings whether orally or in a written format.

- Apply study skills necessary for successful learning.

- Discuss hypotheses, interpret data and produce cogent and analytical practical reports.

- Deploy a high level of analysis and critical judgement in relation to theory and methods.

- Apply skills of mathematical and statistical analysis.

3. Practical skills

- Use techniques for planning and scheduling work/projects.

- Use computers to generate documents to illustrate and clarify arguments.

- Use word-processing and data analysis packages and undertake computer-based literature searches.

- Use interpersonal skills to relate to, and collaborate effectively with, colleagues.

- Use the internet to retrieve and manipulate text and data.

- Manage and process data using spreadsheets and other specialised software packages.

- Use computer skills in a variety of learning contexts.

In addition to deciding what skills each student should be required to achieve as part of the degree programme, it is also necessary to outline the teaching and learning strategies that will be used to ensure that students achieve these goals. These will vary depending on the mode of study and the institution. As an example, the teaching and learning strategies for knowledge and understanding might include the idea that teaching and learning are achieved by lectures supported by seminars, workshops, labs, tutorials, surgeries, etc. It may also be relevant here to include some information about the student support system.

Teaching and learning strategies in relation to cognitive skills might include information about lectures being the starting point for the development of cognitive skills by encouraging students 
to think about the evaluation and application of theories, principles, etc. in different situations. Seminars, tutorials, case studies and lab work might then provide the main vehicles for further development of these skills. In these sessions, students might be encouraged to interact with lecturers and peers, making use of relevant examples, new developments and current research. Creativity of thought and the application of theories to the solution of problems might be developed by the use of case studies and current research done in the main subject areas studied.

Teaching and learning strategies applied to the development of practical skills might include information about library skills, computing skills, etc. Practical skills may be further developed as part of specific units/modules and/or the dissertation component of the degree course. Students might be required to display a range of practical skills as an integral part of work undertaken within various seminars and tutorials. Coursework assignments and the dissertation might require students to make use of all practical skills, such as collecting and interpreting data, applying relevant models, organising and controlling resources, producing reports, and presenting and justifying results and recommendations.

Finally, curriculum skills need to be assessed and it is necessary to ensure that you indicate, generally, how this will be achieved. For example, you could note that assessment is via a mix of continuous assessment and examinations. That continuous assessment might include individual and group work, presentations, essays and assignments.

\section{Key skills}

When designing an undergraduate programme, you need to consider the extent to which you will incorporate key skills and whether it is best to develop these skills in one core unit/module or through a number of units/modules across the programme. There are few units/modules in an economics undergraduate programme that do not develop and assess some key skills; the danger is, though, that a programme develops and assesses one or two key skills extensively while only touching on others. This may become a particular problem if some key skills appear only in optional units/modules, thus resulting in students who do not select these units/modules as part of their degree programme completing the course without having demonstrated proficiency in one or more of the key skill areas.

Creating a key skills map that
only covers core
units/modules can help to
ensure that students on the
programme will have the
opportunity to demonstrate
all key skills despite the
options that they select at
each stage of the degree.

The best way to ensure a balance of key skill development and assessment throughout a programme is to produce a key skills map. This process needs to occur from the unit/module level and feed up to the programme design. Most universities ask unit/module co-ordinators to indicate which skills are taught, practised and/or assessed in their units/modules. This information can then be compiled into a map and enables the programme designer to ensure that all students will gain experience in each key skill at some stage during the degree programme.

\subsection{Unit/module provision and progression}

\section{Models for unit/module progression}

Different institutions use a variety of different models for developing a programme in economics or an economics subject-related area. Some use level 2 to focus heavily on economic theory, providing students with a solid foundation in microeconomics, macroeconomics, quantitative economics and other units/modules that teach largely theoretical material. This is then followed by a diet of level 3 units/modules that focus mainly on the application of the theory learned at 
level 2. Thus units/modules such as trade policy, econometric analysis, European economic integration, etc. would be offered to students at level 3 when they are fully equipped to apply the economic theory to varied and complex subject-specific issues in the field of economics.

A second common model involves students taking some core economic theory at both levels 2 and 3 accompanied by a choice of options in each year. This element of choice then enables a student to select a series of subject-specific applied units/modules which gives them a chance to discover, over the course of a two-year period, which areas of economics most interest them.

These are just two fairly common models of course design and unit/module progression; while some institutions will adhere to these models very strictly, most will use a variation of one of these models in structuring their undergraduate degree programmes.

Other issues that need to be considered in relation to unit/module provision and progression include the number of core units to be incorporated, the number of options that you make available to students at each level, and the provision of electives (units/modules taken from other departments that are not directly related to the study of economics). Again, there is no 'right' model, just advantages and disadvantages to each, some of which are worth noting.

\section{Degree of choice}

Two of the most common structures for undergraduate course design are modularised programmes and linear programmes with a declining core as the student moves through each level of the course. Where a programme is modularised, the different modules tend to include a more varied mixture of students from different courses. This has inevitably resulted in module co-ordinators having to consider carefully the skills that are incorporated into each module and assessing what skills, knowledge and understanding are necessary for students who complete the module.

There is limited scope for incorporating increased choice if you are working within a linear programme framework. The process is certainly made easier at universities that adopt modular programmes, in which more choice is offered, particularly at levels 2 and 3 . This enables students to construct their own pathways through units/modules offered by a range of disciplines. This approach is consistent with subject benchmarking and is popular with students who have participated in this type of programme.

However, the wider choice offered on the modularised programme also makes it more difficult to ensure that students attain key skills and a variety of teaching, learning and assessment patterns during their period of study. Programme design for a modularised course therefore needs to focus mainly on the core elements. Provision of the full range of key skills in the core modules will make the optional units less critical when trying to ensure that students achieve the required key skills throughout a given programme.

Alternatively, linear programmes with a declining core and a restricted set of options are easier to map in the sense that, as long as certain skills are incorporated into a specified number of units, the student will inevitably experience the different skills and learning patterns at some stage of the programme. If you choose to use a declining core format, it may be beneficial to offer a limited degree of option choice at level 1, slightly more at level 2 and extensive choice at level 3. This enables a student to achieve a strong grounding in economic principles at level 1 and effectively design their own degree through levels 2 and 3, whereby they are able to identify their particular area of interest and to tailor their degree to increase their prospects with future employers. This is similar to a modular system except that the degree of choice tends to be somewhat more restrictive.

Alternative degree programme design procedures do not deviate a great deal from those used for single or joint honours degree programmes. Mid-year intake degrees can be more 
complicated to deliver as there may need to be some duplication of unit/module provision and administration (unit/module-related boards, exam boards, etc.), and some additional work in the area of student support. The actual design process, though, varies little from that of a traditional degree programme. Departments that have limited prerequisites and that are modularised would provide a very similar experience to such students despite their entry date. Departments that have a linear programme structure with a declining core and restricted options are more likely to encounter difficulties. These structures also tend to have a greater number of prerequisites and tend to offer less duplication of units/modules, making it more difficult to build required units/modules into a structure that is comprehensive for the students on the programme. Again, this emphasises the fact that the greater the flexibility offered by the department at unit/module level, the easier they are going to find it to design courses that appeal to a wide range of students with differing requirements.

Designing direct entry degrees is also very similar to the design process for a standard undergraduate programme. The principal exception is the learning outcomes of the course, which may need to be broader to accommodate the accredited prior learning offered to the prospective student. Thus it may be unrealistic to expect a student to have achieved certain learning outcomes if these are only offered at level 1 . This is an additional argument for ensuring that the skills that are taught, learned, integrated, practised, reflected upon, assessed, documented and/or developed in the programme are touched upon at all three stages rather than restricted to just one level, which may prove exclusive to those students joining the course directly at levels 2 or 3 .

\section{Structure - cores versus options}

A programme with a majority of core units/modules at each level serves to guide a student through a programme in a very structured manner. Complementing this with the provision of a few options each year gives students the opportunity to take units/modules (generally subjectspecific applied economics units/modules) that they find most interesting and which are, in many cases, related to the field of employment that the student wishes to pursue following graduation. Although very common in the past, this model is becoming somewhat dated with the move by many institutions to create undergraduate programmes that promote choice and student interest. Also, with institutions embracing the ethos of the widening participation agenda, departments are trying to create programmes that can also enable students to 'dip in and out' when it suits. This flexibility is difficult to offer when structures are rigid and the programme core heavily dictates the progression of a student from one level to the next. It is made a little easier if core units/modules are taught more than once throughout a year - that is, during both semesters or in two different terms - although this is unusual. Where there is quite a rigid core structure, these core units/modules tend to be stretched over both semesters/more than one term or offered only once during the academic year.

Alternatively, a programme with a small selection of core units/modules at each level provides students with optimal choice and the ability to tailor their degree course to their future career goals. This type of structure is also more inclusive, as it enables students with other commitments and needs to accumulate units/modules over a period of time that suits them. There is no doubt that the fewer prerequisites there are, the greater degree of choice that is offered to students. Reworking new and existing units/modules so that they can be taught as stand-alone units/modules will aid in the design of mid-year programmes and will give students on all programmes the opportunity to select a more varied diet of units/modules that will help to maximise their potential employability.

With only one or two core units/modules at each level, a student who is taking a limited number of units/modules each year can focus on the core units/modules in one study period and then select options that interest them as and when these units/modules are taught. This is certainly a 
model that students are increasingly seeking when planning their university career. One disadvantage of this model relates to difficulties with timetabling, which become worse when available options are increased. Secondly, this model increases the need for stand-alone units/modules or units/modules where the only co-requisites or prerequisites are the one or two common economics cores that are offered at each level. If this is the case, it might be argued that the students lose the depth of learning, understanding and application that comes from taking a suite of related units/modules that build on each other.

\section{Electives}

Electives are generally considered to be those units/modules that students can select that are unrelated to their programme of study. While this is worth mentioning in any discussion on unit/module provision and course structure, it is not an issue to dwell on here as decisions related to the inclusion of electives are generally made across institutions rather than on a departmental basis. Where electives are available to students, it is always on a limited basis that is, one per year, one per semester, three over the course of the full degree programme (thereby allowing students to take all permitted electives in one year), etc.

Again there are two common models (apart from those that do not have any provision for electives built into their programmes): a restricted elective model and an unrestricted elective model. Where students have an unrestricted list of electives, they can incorporate any units/modules that they choose up to the maximum limit agreed by the university. The main benefit associated with this model is that students are given a very high degree of choice, which, some believe, provides a more rounded education for the students on the programme. Alternatively, the provision of restricted electives is one favoured by a number of institutions, in part due to timetable constraints, and in part due to the preference for students to study units/modules that are in some way related to the field of economics. One exception to this rule tends to be in the area of languages, where students might be given the opportunity to fill an option space each semester/term/year with a language of their choice. There is no doubt that the ability to incorporate a language into an undergraduate degree course is an attractive proposition for many undergraduate students and a choice that can easily influence a student who is selecting an institution for their undergraduate studies.

\section{Specialist versus non-specialist units/modules}

The provision of specialist units/modules for different subject areas used to be quite common (economics for geography, economics for business, etc.). However, pressures on staff time and budgets has forced departments to move away from this model and to create more generic units/modules that are appropriate to a wide range of subject areas. This has resulted in a loss of flavour in the economics units/modules, with examples and readings having to incorporate different subject areas rather than focusing specifically on one area of study.

The only real exception to this is in cases where there is a considerable divide in student knowledge and capability. For instance, a unit/module in econometrics might be a useful tool for students on a variety of non-economics degrees. However, their theoretical background in economics is likely to be significantly less than that of students specialising in economics. Thus mixing the students in one unit/module would disadvantage both groups - non-specialist students would be expected to participate in a unit/module without the necessary skills and knowledge and/or the specialist students would have to take a unit/module that was not drawing fully on their depth of knowledge and understanding of economics. In such cases, there is a strong argument for departments offering two units/modules to accommodate the different needs and abilities of participating students. 
These issues also arise within a suite of undergraduate economics degrees. Students studying for an economics degree or a business economics degree might be well suited to a unit/module in applied econometrics, having studied intermediate and/or advanced microeconomics and macroeconomics at level 2. A student on a joint degree in economics and languages that incorporates slightly less rigorous economics units/modules at level 2 (perhaps units/modules in applied economics and business economics rather than advanced microeconomics and/or macroeconomics) would be better suited to an econometrics unit/module that is slightly less demanding.

Thus the decision that needs to be made when designing an undergraduate degree course is which units/modules can be shared across specialist and non-specialist degrees and which courses require specialist units/modules to ensure that the students involved are provided with a continually challenging selection of units/modules. Note too that these decisions apply equally to joint degrees, mid-year-intake degrees and direct entry degrees. In each case it is essential to consider the mix of units/modules in the degree and the level of theoretical material that is suitable for a student studying in combined subject areas or who is being admitted to a course with accredited prior learning. Then it is necessary to select the sequence and level of units/modules that is most appropriate to the given group of students.

\section{Career, research and study skills units/modules}

Many institutions now require that departments incorporate general units/modules into the undergraduate degree programme that are not directly related to the study of economics, but which no doubt enhance a student's employment potential upon graduation.

Several institutions offer foundation studies/study skills (generally at level 1), which teaches students basic skills related to studying, essay writing, referencing, communication and presentations. Departments that have incorporated such a unit have generally found there to be a considerable return in terms of students' abilities in key skill development and the quality of work that is submitted during the subsequent two years of the degree programme. There are a number of forms of assessment that can be used for such units/modules and you need to select the assessment that best suits the demands and expectations of your particular programme. Some institutions have found that assessing the foundation studies/study skills unit as pass/fail is enough to keep students motivated and can help to cut down on the workload involved in delivery and assessment.

Careers units/modules are also commonly incorporated into the design of undergraduate degree courses. These generally take the form of advising students on how to complete applications, how to produce an impressive curriculum vitae, how to present themselves favourably at interview and how to find the types of job that they are most interested in. Again there are many models for careers units/modules (usually offered at level 2 so that students can use the skills learned when applying for jobs during their final year of study) and the format will vary depending on the demands and needs of the students. As in the case of the study skills unit, using a pass/fail system seems to motivate students to attend and complete the work required, cuts down on the workload of lecturers involved and means that the unit will not then count towards the classification of the student's degree.

Historically, dissertations have been a core element of an undergraduate degree in economics. More recently, however, many institutions have made the dissertation unit/module optional or reduced the weighting of the dissertation in the programme. Moving to an optional or reduced weight dissertation can have its advantages: students who do not perform well in essay/researchbased units/modules can focus more heavily on subjects that reflect their known strengths, and students who have yet to decide what areas of economics most interest them can use the additional options to explore different areas. Alternatively, students who have very specific career goals that do not require them to complete a dissertation can focus their time and attention on units/modules that are likely to help them gain employment in the field of their choice. 
Where the dissertation is a core element in the undergraduate programme, many institutions incorporate a research methods unit/module (most often at level 2) in order to prepare students for the research and writing of a final-year dissertation. These units generally incorporate exercises in effective ways of structuring and presenting research-based work, sourcing, finding key reference material, etc. There is no doubt that units/modules of this nature encourage students to improve their research skills and lead, in most cases, to an improvement in the quality of the dissertation submitted. Thus where a dissertation is an integral part of the undergraduate programme, it is probably a good idea to include a unit that will help them to strengthen their research skills.

\subsection{Making programmes more inclusive}

It is essential that programme design also takes into account the needs of disabled students who might be studying on the new degree course. The QAA Code of Practice: Students with Disabilities asks institutions to:

- Consider making arrangements which ensure that all academic and technical staff:

- plan and employ teaching and learning strategies which make the delivery of the programme as inclusive as is reasonably possible;

- know and understand the learning implications of any disabilities of the students whom they teach and are responsive to student feedback; and

- make individual adaptations to delivery that are appropriate for particular students, which might include providing handouts in advance and/or in different formats, short breaks for interpreters to rest, or using radio microphone systems, or flexible/interrupted study for students with mental health difficulties.

While many of the necessary considerations need to be made at the unit level, the programme design and accompanying learning outcomes need to recognise the needs of students with differing abilities. At the level of programme design, ensuring accessibility is most evident in the learning outcomes and the assessment that will be used in order for a student to achieve these

TOP

\section{TIPS}

Consulting the institution's disability officer in the initial stages of course design can provide valuable insight into the degree to which the new programme will be attractive and inclusive for students with varying disabilities. goals. Thus a learning outcome that requires students to demonstrate an ability to communicate effectively orally through individual and group presentations might be too restrictive. For example, a student who is visually or aurally impaired might, by the nature of their disability, be unable to achieve this learning outcome successfully. Therefore a more general outcome that requires students to communicate effectively issues relevant to the economics subject area might be considered a more inclusive learning outcome for those students who are unable to participate in an assessment mode that is limited to presentations.

Ultimately, programme design that incorporates substantial choice will be accessible to a wider range of students. Programmes with flexible study patterns, stand-alone modules/units that do not have to be completed in a strict order, extensive choice of options and flexible modes of delivery and assessment will be more inclusive. Also, incorporating flexibility into programme design acknowledges that there are many ways of demonstrating competence in relation to clearly defined course objectives. This can mean making available to, or developing with, students a variety of ways of demonstrating programme specific learning. 


\section{Appendix \\ BA Economics: an example of a programme specification}

\section{Rationale}

Include information about:

- potential demand for the new course (using marketing information from the UCAS website);

- main competitors;

- the gap in the market that would be filled by the provision of this programme;

- distinctive features of the programme;

- target recruitment.

\section{Educational aims}

- To provide an in-depth knowledge of economics and to enable students to apply the knowledge and understanding gained in this subject area.

- To enable students to study and apply the principles of economics to different types of practical situation that will be useful for future employment.

- To encourage ongoing critical, evaluative and strategic ways of thinking in all areas.

- To recognise the importance of the industry-education relationship and to offer opportunities for learning in other environments.

- To enable students to undertake relevant postgraduate study.

- To provide successful graduates of the programme with an educational and training profile that will equip them for employment in a range of sectors.

\section{Outcomes}

\section{Programme outcomes}

To complete the course successfully and gain the award the student will have demonstrated the ability to critically evaluate and apply the theories and techniques of economics. Specifically, students will acquire:

\section{A Knowledge and understanding of:}

A1 Fundamentals/principles of economics

A2 The basic tools of economic analysis

A3 Economic theory and practice 
A4 Quantitative methods and computing techniques relevant to the study of economics

A5 The use of data, both quantitative and qualitative, relevant to the study of economics

A6 The relevance of economics to the study of society

A7 The application of specialist knowledge

\section{Teaching and learning strategies and methods}

Teaching and learning are achieved by lectures supported by seminars, workshops and surgery sessions. The understanding of theory taught is reinforced by the arrangement of common core units in each year. Pastoral support is provided by the departmental duty tutor system, which has strong operational links with the course management team.

\section{Assessment}

Assessment is via a mixture of continuous assessment and exam. Continuous assessment includes individual and group work, presentations, essays and assignments.

\section{B Cognitive (intellectual or thinking) skills - able to:}

B1 Identify, define and explore economic issues [using logical and creative approaches]

B2 Identify tacit assumptions and limitations of data and information

B3 Analyse and evaluate evidence

B4 Expound findings whether orally or in a written format

B5 Apply study skills necessary for successful learning

B6 Discuss hypotheses, interpret data and produce cogent and analytical practical reports

B7 Deploy a high level of analysis and critical judgement in relation to theory and methods

B8 Apply skills of mathematical and statistical analysis

\section{Teaching and learning strategies and methods}

Lectures will provide the starting point for the development of cognitive skills by means of encouraging students to think about the evaluation and application of theories, principles, etc. in different situations. Seminars, tutorials, case studies and lab work will then provide the main vehicle for further development of these skills. In these sessions, students will be encouraged to interact with lecturers, peers and practitioners, making use of relevant examples, new developments and current research. Creativity of thought and application of theories to the solution of problems will be developed by the use of case studies and current research done in the main subject areas studied.

\section{Assessment}

All cognitive skills will be assessed by means of seen and unseen written examinations and/or continuous assessment.

\section{Practical (professional or subject specific) skills - able to:}

C1 Use techniques for planning and scheduling work/projects

C2 Use computers to generate documents (graphs, charts, etc.) to illustrate and clarify arguments 
C3 Use word-processing and data analysis packages, and undertake computer-based literature searches

C4 Use interpersonal skills to relate to, and collaborate effectively with, colleagues

C5 Use the internet to retrieve and manipulate text and data

C6 Manage and process data-using spreadsheets and other specialised software packages

C7 Use computer skills in a variety of learning contexts

\section{Teaching and learning strategies and methods}

As part of the development of practical skills, all students will be provided with an introduction to the library and other key sources of information (including electronic) as part of the course induction programme. Practical skills will be further developed as part of specific units and the dissertation component of the degree course. Students will be required to display a range of practical skills as an integral part of work undertaken within various seminars and tutorials. Coursework assignments and the dissertation will require students to make use of all practical skills, collecting and interpreting data, applying relevant models, organising and controlling resources, producing reports, and presenting and justifying results and recommendations.

\section{Assessment}

Seen and unseen written examinations will be used to assess some practical skills. These and all other practical skills will be assessed within coursework assignments and the dissertation. As part of the coursework and dissertation, students will be required to present and justify complex arguments and to provide evidence of their ability to organise and control resources in order to meet output targets.

D Transferable and key skills - able to:

D1 Communicate effectively using graphical, written, verbal and IT means

D2 Use information technology

D3 Engage in problem solving

D4 Apply number skills appropriate to the field of economics

D5 Improve own learning and performance

D6 Work with others as an effective team member

\section{Teaching and learning strategies and methods}

Acquiring key skills is integral to all activities within the course programme. Students will develop skills in the use of information technology for collecting, analysing and presenting information and data in a number of units. Seminar and tutorial sessions provide a means of developing all key skills, with a particular emphasis on communication skills and working with others. The key skills of application of number and problem solving will be emphasised throughout the course, with specific emphasis on these areas in the quantitative and workshop units taught throughout the course. These skills will then be further tested when students apply their quantitative knowledge to subject areas such as managerial economics, industrial economics, applied economics and business economics. Students will be encouraged to monitor and improve their own learning and performance throughout the course. These skills, and working with others, will also be essential elements of the dissertation undertaken at level 3. 


\section{Assessment}

Unseen and written examinations, coursework and the dissertation will all contribute towards assessing the key skills listed.

\section{Programme structure}

The course is offered in full-time mode over three years. Each academic year consists of two semesters. Progression to the next level is dependent on achieving 120 credits at the previous level.

\section{Sample course structure:}

\section{Linear programme structure with a declining core and restricted options} BA Economics

\section{Stage 1}

\begin{tabular}{|l|l|l|l|l|l|l|}
\hline Semester 1 & $\begin{array}{l}\text { Quantitative } \\
\text { Economics 1 }\end{array}$ & $\begin{array}{l}\text { Introduction } \\
\text { to Economics }\end{array}$ & $\begin{array}{l}\text { Britain and } \\
\text { the } \\
\text { International } \\
\text { Economy }\end{array}$ & $\begin{array}{l}\text { Foundation } \\
\text { Studies }\end{array}$ & $\begin{array}{l}\text { Current } \\
\text { Economic } \\
\text { Issues } \\
1\end{array}$ & OPTION \\
\hline Semester 2 & $\begin{array}{l}\text { Statistical } \\
\text { Analysis for } \\
\text { Economists }\end{array}$ & $\begin{array}{l}\text { Micro- } \\
\text { economics }\end{array}$ & $\begin{array}{l}\text { Macro- } \\
\text { economics }\end{array}$ & $\begin{array}{l}\text { Economics } \\
\text { Workshop 1 }\end{array}$ & $\begin{array}{l}\text { Current } \\
\text { Economic } \\
\text { Issues 2 }\end{array}$ & OPTION \\
\hline
\end{tabular}

Options: Introduction to Accounting (S1 \& S2), Science, Technology and Society (S1), English Legal System (S1), General Principles of Contract Law (S2), Business and Financial History (S2), Language (S1 \& S2)

\section{Stage 2}

\begin{tabular}{|l|l|l|l|l|l|l|}
\hline Semester 1 & $\begin{array}{l}\text { Intermediate } \\
\text { Macro- } \\
\text { economics }\end{array}$ & $\begin{array}{l}\text { Intermediate } \\
\text { Micro- } \\
\text { economics }\end{array}$ & $\begin{array}{l}\text { Economics } \\
\text { Workshop 2 }\end{array}$ & $\begin{array}{l}\text { Quantitative } \\
\text { Economics 2 }\end{array}$ & OPTION & OPTION \\
\cline { 1 - 5 } Semester 2 & & $\begin{array}{l}\text { Personal and } \\
\text { Career } \\
\text { Development }\end{array}$ & $\begin{array}{l}\text { Introduction } \\
\text { to } \\
\text { Econometrics }\end{array}$ & OPTION & OPTION \\
\hline
\end{tabular}

Options: Economics of Insurance and Investment (S1), Banking and Financial Structures (S1), Introduction to Environmental Management (S1), Economics of Technical Innovation (S1), Introduction to International Trade (S2), Business Law (S2), Economic Foundations of Investment and Finance (S2), Language (S1 \& S2) 
Stage 3

\begin{tabular}{|l|l|l|l|l|l|l|}
\hline Semester 1 & $\begin{array}{l}\text { Further } \\
\text { Macro- } \\
\text { economics }\end{array}$ & OPTION & OPTION & OPTION & OPTION & OPTION \\
\hline Semester 2 & $\begin{array}{l}\text { Further } \\
\text { Micro- } \\
\text { economics }\end{array}$ & OPTION & OPTION & OPTION & OPTION & OPTION \\
\hline
\end{tabular}

Options: Regional and Local Economic Analysis (S1), Development of Globalisation (S1), ECommerce - a Critical Evaluation (S1), International Trade Policy (S1), European Economic Integration (S1), Economics of Corporate Finance (S1), Economics of International Financial Management (S1), Project Appraisal (S1), Project Management (S1), Business Forecasting Using Time-Series Models (S1), Econometric Analysis (S2), Game Theory (S2), Marine Resource Economics (S2), International Banking (S2), Classical and Radical Economic Ideas (S2), Business Finance and the Financial Environment (S2), Economics of Corporate Investment Policy (S2), South American Economies (S2), European Community Law (S2), Discrimination and Conflict in Employment Law (S2), Taxation (S2), Dissertation (S1 \& S2), Language (S1 \& S2)

\section{$5 \quad$ Admissions}

\section{Entry to Year 1}

High School Certificate or Diploma (grades average or GPA $x x$ )

or Form XII (grades over $x x \%$ )

or International Baccalaureate ( $x x$ pts)

A-level ( $x x$ pts) or $x x x$ UCAS Tariff Points

and GCSE Maths (Grade $x$ ) or equivalent

English - IELTS $x$ or TOEFL $x x x$ ( $x x x$ computer version)

Minimum age $x x$

\section{Progression}

\section{Exit Award (3)}

BA (Hons) degree - 360 credits

Adv. Dip. HE - 300 credits

\section{Exit Award (2)}

Dip. HE - 240 credits (maximum 120 level 1)

Adv. Cert. HE - 180 credits

\section{Exit Award (1)}

Cert. HE - 120 credits 


\section{$7 \quad$ Key skills mapping}

Example: level 1, semester 1, core units only

\begin{tabular}{|c|c|c|c|c|c|c|c|c|c|c|c|c|c|c|c|c|c|c|c|c|}
\hline \multirow[b]{3}{*}{ Unit name } & \multicolumn{17}{|c|}{ Key Skills Level 3 (unless stated otherwise) } & & & \\
\hline & \multicolumn{4}{|c|}{ Communication } & \multicolumn{3}{|c|}{$\begin{array}{l}\text { Information } \\
\text { Technology }\end{array}$} & \multicolumn{3}{|c|}{$\begin{array}{l}\text { Application } \\
\text { of Number }\end{array}$} & \multicolumn{4}{|c|}{ Problem Solving } & \multicolumn{3}{|c|}{$\begin{array}{l}\text { Learning and } \\
\text { Performance }\end{array}$} & \multicolumn{3}{|c|}{$\begin{array}{c}\text { Working with } \\
\text { Others }\end{array}$} \\
\hline & $\mathrm{C} 3.1$ & $\mathrm{C} 3.2$ & C3.3 & C3.4 & $\mathrm{I} 3.1$ & $\mathrm{I} 3.2$ & $\mathrm{I} 3.3$ & N3.1 & N3.2 & N3.3 & P3.1 & P3.2 & P3.3 & P3.4 & L3.1 & $\mathrm{L} 3.2$ & $\mathrm{~L} 3.3$ & W3.1 & W3.2 & W3.3 \\
\hline \multicolumn{21}{|l|}{ Level 1} \\
\hline $\begin{array}{l}\text { Quantitative } \\
\text { Economics }\end{array}$ & $\mathrm{X}$ & $\mathrm{x}$ & & & $\mathrm{x}$ & & & $\mathrm{x}$ & $\mathrm{x}$ & $\mathrm{x}$ & $\mathrm{X}$ & & & $\mathrm{X}$ & $\mathrm{X}$ & & & $\mathrm{X}$ & & \\
\hline $\begin{array}{l}\text { Introduction } \\
\text { to Economics }\end{array}$ & & & $\mathrm{x}$ & & & & & $\mathrm{x}$ & $\mathrm{x}$ & & $\mathrm{x}$ & & & & & $\mathrm{x}$ & & & & \\
\hline $\begin{array}{l}\text { Britain } \\
\text { and the } \\
\text { International } \\
\text { Economy }\end{array}$ & & & $\mathrm{x}$ & & & & & $\mathrm{x}$ & $\mathrm{x}$ & & $\mathrm{x}$ & & & & & $\mathrm{x}$ & & & & \\
\hline $\begin{array}{l}\text { Foundation } \\
\text { Studies }\end{array}$ & $\mathrm{x}$ & $\mathrm{x}$ & $\mathrm{x}$ & & & & & & & & & & & & $\mathrm{x}$ & $\mathrm{x}$ & & $\mathrm{x}$ & $\mathrm{x}$ & \\
\hline $\begin{array}{l}\text { Current } \\
\text { Economic } \\
\text { Issues } 1\end{array}$ & $\mathrm{x}$ & & & & & $\mathrm{x}$ & & & & & & & & & & & & & $\mathrm{X}$ & \\
\hline
\end{tabular}

\section{Assessment mapping}

Example: level 1, semester 1, core units only

\begin{tabular}{|c|c|c|c|c|c|c|c|}
\hline \multirow[b]{2}{*}{ Unit name } & \multicolumn{4}{|c|}{ Coursework } & \multicolumn{3}{|c|}{ Examination } \\
\hline & Total (\%) & Essay & Presentation & $\begin{array}{c}\text { In-class } \\
\text { test }\end{array}$ & Total (\%) & Mode & $\begin{array}{c}\text { Duration } \\
\text { (hrs) }\end{array}$ \\
\hline \multicolumn{8}{|l|}{ Level 1} \\
\hline $\begin{array}{l}\text { Quantitative } \\
\text { Economics }\end{array}$ & 50 & & & 50 & 50 & & 2 \\
\hline $\begin{array}{l}\text { Introduction } \\
\text { to Economics }\end{array}$ & 25 & & & 25 & 75 & & 1.5 \\
\hline $\begin{array}{l}\text { Britain } \\
\text { and the } \\
\text { International } \\
\text { Economy }\end{array}$ & 40 & 20 & 20 & & 60 & & 1.5 \\
\hline $\begin{array}{l}\text { Foundation } \\
\text { Studies }\end{array}$ & 100 & 20 & 20 & 20 & 40 & & 1 \\
\hline $\begin{array}{l}\text { Current } \\
\text { Economic } \\
\text { Issues } 1\end{array}$ & 60 & 30 & 30 & & 40 & & 1.5 \\
\hline
\end{tabular}




\section{Curriculum skills mapping}

Example: level 1, semester 1, core units only

\begin{tabular}{|c|c|c|c|c|c|c|c|c|c|c|c|c|c|c|c|c|c|c|c|c|c|c|c|c|c|c|c|c|}
\hline \multicolumn{29}{|c|}{ Programme outcomes } \\
\hline Unit name & A1 & A2 & A3 & A4 & A5 & A6 & A7 & B1 & B2 & B3 & B4 & B5 & B6 & B7 & B8 & C1 & $\mathrm{C} 2$ & C3 & C4 & C5 & C6 & C7 & D1 & D2 & D3 & D4 & D5 I & 56 \\
\hline Level 1 & & & & & & & & & & & & & & & & & & & & & & & & & & & & \\
\hline $\begin{array}{l}\text { Quantitative } \\
\text { Economics }\end{array}$ & $\mathrm{x}$ & $\mathrm{x}$ & $\mathrm{x}$ & $\mathrm{x}$ & $\mathrm{x}$ & & $\mathrm{x}$ & & & $\mathrm{x}$ & $\mathrm{x}$ & $\mathrm{x}$ & & & & $\mathrm{x}$ & & & & & & $\mathrm{x}$ & $\mathrm{x}$ & $\mathrm{x}$ & $\mathrm{x}$ & $\mathrm{x}$ & $\mathrm{x}$ & $\mathrm{x}$ \\
\hline $\begin{array}{l}\text { Introduction } \\
\text { to Economics }\end{array}$ & $\mathrm{x}$ & $\mathrm{x}$ & $\mathrm{x}$ & & & $\mathrm{x}$ & & & & $\mathrm{x}$ & & $\mathrm{x}$ & & & $\mathrm{x}$ & $\mathrm{x}$ & & & & & & $\mathrm{x}$ & & $\mathrm{x}$ & $\mathrm{x}$ & $\mathrm{x}$ & & \\
\hline $\begin{array}{l}\text { Britain } \\
\text { and the } \\
\text { International } \\
\text { Economy }\end{array}$ & & $\mathrm{x}$ & $\mathrm{x}$ & $\mathrm{x}$ & & & $\mathrm{x}$ & & & & $\mathrm{x}$ & & $\mathrm{x}$ & & & $\mathrm{x}$ & $\mathrm{x}$ & & & & & & $\mathrm{x}$ & & $\mathrm{x}$ & $\mathrm{x}$ & $\mathrm{x}$ & \\
\hline $\begin{array}{l}\text { Foundation } \\
\text { Studies }\end{array}$ & & & & & & & & & & & & & & & & $\mathrm{x}$ & & $\mathrm{x}$ & $\mathrm{x}$ & & $\mathrm{x}$ & $\mathrm{x}$ & & & $\mathrm{x}$ & & $\mathrm{x}$ & $\mathrm{x}$ \\
\hline $\begin{array}{l}\text { Current } \\
\text { Economic } \\
\text { Issues } 1\end{array}$ & $\mathrm{x}$ & $\mathrm{x}$ & $\mathrm{x}$ & $\mathrm{x}$ & $\mathrm{x}$ & $\mathrm{x}$ & & & $\mathrm{x}$ & $\mathrm{x}$ & $\mathrm{x}$ & $\mathrm{x}$ & $\mathrm{x}$ & & & & $\mathrm{x}$ & $\mathrm{x}$ & & $\mathrm{x}$ & & & $\mathrm{x}$ & $\mathrm{x}$ & $\mathrm{x}$ & & & $\mathrm{x}$ \\
\hline
\end{tabular}

\section{Support for student learning}

Students will have access to university facilities. A wide range of support for student learning is provided, including:

- an induction programme on entry;

- library provision;

- online access to electronic journals and databases;

- extensive computer facilities, including personal email accounts and access to the internet;

- academically qualified staff with relevant experience, including research, consultancy and links with industry;

- access to learning support facilities;

- pastoral care, with all students having a personal tutor and dissertation supervisor;

- access for all students to university student counsellors, welfare and careers advice.

\section{Evaluation and additional information}

a Mechanisms for review and evaluation

- Unit review

- External Examiners' comments and reports

- Reports to Board of Teachers and Board of Studies

- Annual Course Report to Department of Economics Departmental Quality Review 


\section{b Responsibilities for monitoring and evaluation}

- Course Leader

- Course Management Team

- Board of Studies

- Economics Departmental Quality Review

- Unit Assessment Board and Award Board of Examiners

c Mechanisms for gaining student feedback

- Informal feedback from students via unit co-ordinators and personal tutors

- Formal feedback from individual students via unit evaluation questionnaires and course evaluation forms

- Formal feedback from student representatives on Staff-Student Consultative Committee and Board of Studies

- Meetings with external examiners

\section{d Staff development priorities}

Identified via:

- Unit evaluation

- Meetings of Course Management Team

- Additional information may be found in:

- Course Approval Documents

- Student Handbook

- Undergraduate Prospectus

- Assessment Regulations

- Quality Assurance Agency Quality Assessment Report

- Quality Assurance Agency Quality Audit Report

- University web pages 


\section{References and bibliography}

Ashcroft, K. (1995) The Lecturer's Guide to Quality and Standards in Colleges and Universities, Falmer Press, London.

Bennett, N., Dunne, E. and Carre, C. (2000) Skills Development in Higher Education and Employment, Society for Research into Higher Education/Open University Press, London.

Biggs, J. (1999) Teaching for Quality Learning at University, Society for Research into Higher Education/Open University Press, Buckingham.

Fry, H., Ketteridge, S. and Marshall, S. (1999) A Handbook for Teaching and Learning in Higher Education. London: Kogan Page.

Higher Education Quality Council (1996) Understanding Academic Standards in Modular Frameworks, London: HEQC.

Livingstone, I. and Matthews, H. (2000) Assessing and Recording a Skills-based Curriculum, Cheltenham: Geography Discipline Network.

Murphy, R. (2001) A Briefing on Key Skills in Higher Education, Assessment Series 5, Learning and Teaching Support Network (LTSN), York.

Rust, C. and Gibbs, G. (eds) (1997) Improving Student Learning through Course Design, Oxford Centre for Staff and Learning Development, Oxford.

Shaw, S. (2000) Teachability: Creating an Accessible Curriculum for Students with Disabilities, Scottish Higher Education Funding Council, Strathclyde.

Toohey, S. (1999). Designing Courses for Higher Education, Society for Research into Higher Education/Open University Press, Buckingham.

\section{Websites}

DfEE Key Skills projects: www.dfes.gov.uk/keyskills/faq.shtml

Innovations Team: www.innovations.ac.uk

Teachability Project: www.ispn.gcal.ac.uk/teachability/index.html

Skills plus: www.open.ac.uk/vqportal/Skills-Plus

LTSN Generic Centre subject benchmarking:

www.ltsn.ac.uk/genericcentre/projects/sub-benchmark/resource_area.asp

QAA: www.qaa.co.uk

South East England Development Agency: www.seeda.co.uk

UCAS: www.ucas.ac.uk 